\title{
The hidden hierarchy of far-right digital guerrilla warfare
}

\author{
Letícia Cesarino $^{1}$ Pedro H. J. Nardelli ${ }^{2}$
}

Accepted: 15 May 2021 / Published online: 9 June 2021

(c) The Author(s) 2021

\begin{abstract}
The polarizing tendency of politically leaned social media is usually claimed to be spontaneous, or a by-product of underlying platform algorithms. This contribution revisits both claims by articulating the digital world of social media and rules derived from capitalist accumulation in the post-Fordist age, from a transdisciplinary perspective articulating the human and exact sciences. Behind claims of individual freedom, there is a rigid pyramidal hierarchy of power heavily using military techniques developed in the late years of the cold war, namely Russia Reflexive Control and the Boyd's decision cycle in the USA. This hierarchy is not the old-style "command-and-control" from Fordist times, but an "emergent" one, whereby individual agents respond to informational stimuli, coordinated to move as a swarm. Such a post-Fordist organizational structure resembles guerrilla warfare. In this new world, it is the far right who plays the revolutionaries by deploying avantgarde guerrilla methods, while the so-called left paradoxically appears as conservatives defending the existing structure of exploitation. Although the tactical goal is unclear, the strategic objective of far-right guerrillas is to hold on to power and benefit particular groups to accumulate more capital. We draw examples from the Brazilian far right to support our claims.
\end{abstract}

Keywords Cyber guerrilla $\cdot$ Far right $\cdot$ Social media $\cdot$ Post-Fordism

\section{Introduction}

The polarizing tendencies of politically leaned social media such as Twitter and Facebook are often claimed to be selforganized, following simple behavioral rules which lead to the emergence of echo chambers or filter bubbles (Cinelli 2021). Rather than regarding such phenomena as either spontaneous or a by-product of underlying platform algorithms, this contribution seeks to articulate the digital world of social media with rules derived from capitalist accumulation in the post-Fordist age (Srnicek 2017). It draws on a transdisciplinary perspective articulating the expertise of both authors in the human and exact sciences to bear on the Brazilian far-right's communicational strategies during and after the election of Jair Bolsonaro in 2018 (Cesarino 2019, 2020). It explores the broader hypothesis that, behind claims to individual freedom, there is a rigid pyramidal hierarchy of

Pedro H. J. Nardelli

pedro.nardelli@lut.fi

1 Federal University of Santa Catarina (UFSC), Florianópolis, Brazil

2 Lappeenranta-Lahti University of Technology (LUT), Lappenranta, Finland power deploying military techniques developed in the late years of the Cold War, namely Russia's Reflexive Control (Jaitner and Kantola 2016) and US Colonel John Boyd's decision cycle (Leirner 2020). This is not the "commandand-control" hierarchy from Fordist times, but rather an "emergent" one, whereby individual agents respond to informational stimuli and are coordinated to move as a swarm.

Such a post-Fordist organizational structure makes up what Boyd calls a "guerrilla." In this new world, it is the far right who plays the revolutionaries by deploying avant-garde guerrilla methods, while the so-called left paradoxically acts as conservatives defending the existing structure of exploitation. We suggest that today's revolutionary avant-garde dominates the digital environment by: (1) understanding the swarm behavior's predictable polarizing dynamics as a relation between behavioral rules and individual actions; (2) embracing the randomness emerging from the chaotic nature of interactions between individual agents, which nonetheless results in easy-to-guide swarms at the macro-level; (3) engaging support for their guerrilla operation by robots and persons reacting to signals by "influencers," thus guiding the swarm to form a social laser that directs its energy toward focused targets; and (4) setting the agenda by means of its own inconsistency, thus keeping the environment suitable 
for interventions. Although the tactical goal is not clear and depends on the specific country under consideration, the strategic objective of far-right guerrillas is to hold on to power and benefit particular groups to accumulate more capital. In the Brazilian case, these comprise the multiple segments that make up what has been called "Bolsonarism," particularly its militaristic, evangelical, alt-right and libertarian core (Goldstein 2019).

\section{Social media dynamics and active guerrilla terrain}

From the point of view of users, discourse and behavior on social media may often appear as random and chaotic. Viral memes, political and moral polarization, cancel culture, fake and true news, echo chambers, have populated the digital landscape in Brazil and elsewhere, becoming particularly dazzling during electoral periods. Part of the literature may reproduce this perspective, by reducing observable processes to polarizing patterns that are supposedly a by-product of underlying algorithms determining individual "feeds," thus increasing the priority of content with higher chances of being "liked" or "clicked." The dynamics of social media would thus emerge from individual spontaneous behavior in a kind of self-organization generated, reverberated or inflated by the platforms' business models, leading to a destructive creation (Merrin, W., Hoskins 2020) or threats in epistemic security (Seger et al. 2020). Although this may be empirically correct, it does not get at deeper structural relations that not only organize those processes, but also afford their very existence.

This narrow understanding generally accompanies simple solutions for such socio-political problems, which are then reduced to: (1) educating users to behave appropriately on social media, and (2) regulating and reforming platforms and their business model toward including more "ethical" algorithms, aligned with "for good" corporate policies. These and other related solutions might be useful tools to change particular traits of social media (Oates 2020), but here we argue they fall short of solving the structural problems that are the root of those observable phenomena.

What follows is an attempt to identify hidden hierarchical power structures typical of post-Fordism by articulating: (a) the unintended, "under the radar" yet systemic effects of platform architectures (Abdin 2021; Gray et al. 2020), (b) the hidden power structures stimulating conflict, converting social media into a "war zone" whose "terrain" is favorable to cyber guerrilla and (c) struggles for political power underlying such cyber-operations, involving post-Fordist competition among economic agents (i.e., the corporations and nations which will control capital accumulation, nationally and internationally).

Individualized feeds are the "terrain" of social media viewed as a guerrilla battlefield (Van Haaster, Gevers and Sprengers 2016). They are the output of algorithms that interactively process as inputs users' activities, actions, reactions and interactions, as well as other contextual data such as trending topics and paid advertisements. The social media terrain is therefore active and dynamic, thus affording "environments" that encourage users to stay connected and active through addictive reward systems and other elements of architecture design (Chun 2016). In such an environment, it is possible to induce trends by creating controversies around outrageous content so that a collective behavior of users can be identified. We argue here that the main question to be asked is not how algorithms, business models or users lead to the aforementioned phenomena but rather, (1) what are the mechanisms employed by a small group of users to generate such observed dynamics of social media as part of digital guerrilla warfare, (2) who are such users and (3) what are their stakes.

These mechanisms are well known in the literature on multi-agent systems, where simple decision rules lead to group coordination to form engineered swarms (Brambilla et al. 2013). Swarms, as self-organized systems, are defined by relatively autonomous agents that answer to external stimuli following simple heuristics or rules of thumb (Kühnlenz and Nardelli 2016; Kühnlenz, Nardelli and Alves 2018; Nardelli and Kühnlenz 2018). Note, however, that not all heuristics lead to swarm behavior: they either emerge in non-teleological open-ended evolutionary processes or are engineered toward specified goals.

\section{The hidden hierarchy of the digital guerrilla}

Our thesis is that a small group identified with a far-right political position and with deep knowledge about the social media terrain may be able to produce a favorable polarized environment which affords inducing "thinking humans" to act as "reactive robots." Real bots are also employed in order to amplify trends, but with a relatively limited reach (González-Bailó and De Domenico 2021). This strategy converges with the temporality of permanent crisis implicit in contemporary platform architectures, where users are continuously interpellated by "events" that demand one's attention and intervention (Chun 2016).

In the 2018 Brazilian elections, for instance, it was common for users in the pro-Bolsonaro ecosystem to be given small tasks on a regular basis. During the campaign, this usually involved prompts to de-like anti-Bolsonaro celebrities, attack political enemies and journalists, or inspect for fraud by taking pictures of electronic ballots during the 
vote. Discursive patterns looped both ways: from leader to followers, while also being crowdsourced from the latter. In the aftermath of a knife attack the candidate suffered one month from the first round, this pattern intensified, as users took on the campaign on Bolsonaro's behalf (Cesarino 2019). Spontaneous and orchestrated, organic and automated agency became blurred in the burgeoning ecosystem of self-proclaimed Jair's Army, Jair's shield, Jair's marketing agents or Bolsonaro's robots. The cyber-guerrilleros also act like post-Fordist "entrepreneurs of the self" (Dardot and Laval 2014), like political versions of the (infamous) Amazon mechanical turk.

It is also interesting to note how the cyber guerrilla resonates with the post-Fordist approach of control in warfare (King 2006). The typical management in Fordist periods was command-and-control, which is centralized with a clear hierarchy of power. This is still how military institutions are organized. In contrast, post-Fordist organizations (also identified with neoliberalism or postmodernism) are based on platform structures that offer individuals the autonomy to subject themselves to their rules (Chun 2016). As in traditional guerrillas, there is a hierarchy that is usually decentralized, based on cells and self-identification with their moral rules (Van Haaster et al. 2016). This leads to a situation where individuals in higher positions can command without responsibility while lower-ranked soldiers act with relative autonomy but, as a drawback, take full responsibility for their own actions. Similarly, in platform environments, individual users experience full sovereignty and freedom over their small digital fiefdoms, while largely ignoring the opaque influence of algorithmic systems (Chun 2016). Bolsonaro's communication strategy during the pandemic makes evident such de-responsibilization effects, since a significant share of the population does not seem able to trace causality, and therefore accountability, back on to him (Cesarino 2021). Guerrilla warfare in social media then resembles a platform business model: anyone can be a guerrillero with full autonomy to act, subject only to the group's moral rules, just like anyone with a car can be an Uber driver as far as he/she accepts to submit to platform rules (Srnicek 2017).

Like in techno-psychological military attacks in observe-orient-decide-act (OODA) cycles (Boyd 1987) or techniques of reflexive control (Jaitner and Kantola 2016), the actions and energy from the enemy camp were also put to work on Bolsonaro's behalf by taking advantage of affordances that were already available in the platforms. Twitter hashtags for instance afford the kind of recursive, escalating opposition that anthropologist and cyberneticist Gregory Bateson (1958) called schismogenesis. The Bolsonarist camp actively evinced schismogenic response from their enemies ("the left") by introducing hashtags mimicking their form but inverting content, such as \#EleNão (NotHim) versus \#EleSim (YesHim) or \#ElasNão (NotThem-in this case, feminists). Reverse mimesis of the enemy was an otherwise common move, implicit in the design of pro-Bolsonaro binary memes, slogans and logos (Cesarino, in print). Similar patterns are also found in the supporters of Donald Trump in the USA (Merrin 2019).

A relevant parallel here is the ideological struggle in scientific organizations of Stalin's USSR after World War II (Gerovitch 2004). Scientists were autonomous but lived in a state of permanent crisis subjected to strict behavioral rules, informally defined by the Party's command line via influential publications. Deviants were canceled from the mainstream. The strategy was to force the scientists to select one side (e.g., either one is pro-Lyssenko, or against him), and thus, subordinate to the "rules of the game" in order to remain active in Soviet science. The scientists' self-organization was governed by a strict Party hierarchy mostly through informal norms. The political line was rarely indicated explicitly by Party leaders themselves, but rather textually signaled in Soviet scientific or philosophical publications.

In both cases, of social media and the USSR., there is a decentralized but hierarchical decision-making system. During the 2018 campaign in Brazil, the pro-Bolsonaro ecosystem on WhatsApp was constructed around large public groups with a poli-centric, hierarchical "hydra-like" structure (Santos et al. 2019). At the lowest levels of the hierarchy, there is relative autonomy for creating memes, canceling persons at will or creating new quarrels. However, such autonomy is limited by signals originating from a higher-level group (e.g., influencers or core leaders themselves, such as Jair Bolsonaro and his sons). Most often, followers already know how to respond to offline events. But whenever there are unexpected, high profile events, it is possible to note a time lag between the timing of the event itself and the response at network peripheries. This was the case for instance when Justice Minister Sergio Moro quit the Bolsonaro government early on during the pandemic, or when corruption charges against former President Lula were canceled one year later. It is as if most users will wait for the "narrative" to arrive before they can go on reproducing it. The bottom line is that there are only two possible options in order to be active and visible in social media: to be either pro or con.

In this context, the cyber guerrilla led by a far-right avant-garde may employ well-known military informational operations such as smokescreening, false flagging and firehosing (Leirner 2020). The idea is to increase the uncertainty (or information entropy) of individuals with respect to existing formal structures of power, always questioning their foundations and therefore helping corrode societal trust in the scientific, political and legal systems. Much like the "merchants of doubt" (Oreskes and 
Conway 2011) of the tobacco and fossil fuel industries, the aim is to sustain environmental entropy, or equiprobability, at high levels. Such environments do not favor deliberation but rather simple decision heuristics like "follow the influencer," or algorithmic instructions like "if my enemy is for it, then I am against it." By managing such terrain, the far-right avant-garde decreases the uncertainty of actions taken by the users, generating a systemic state favorable for cyber-operations. In other words, the far right is capable of guiding the social media terrain where the two polarizing groups form highly predictable swarms in an environment characterized by operational uncertainty.

\section{What are the interests backing (and banking) the far-right digital guerrilla?}

The far-right strategy operates not only on the cyberworld, as any cyber guerrilla (Van Haaster, Gevers and Sprengers 2016), but also (and more importantly) aims at mass support within the population for both reactionary social policies and a neoliberal economic agenda. It seems likely that the far-right avant-garde found in social media a weak link for inducing social schismogenesis via informational operations based on interventions in OODA cycles through reflexive control tools. However, as Bolsonaro and his supporters' attempts to stimulate attacks against the Brazilian Supreme Court illustrate, the unclear imputation of responsibility and inconsistent behavior indicate the lack of a thorough plan of action typical of Fordism. It is more like the emergent "let's see what happens" postFordist style of action, which embraces unpredictability and performativity (Mirowski 2019). If the proposed actions do get popular support, they can perhaps seize power; otherwise, they can just put aside responsibility by blaming other individuals or organizations.

Behind the political struggle, there are also geopolitical movements related to national and international economic powers. Transnational platforms, multinational corporations and outsourcing, new players in information and communication technology (mainly in standardized solutions like 5G), disputes for fossil fuels and raw materials for the "green new deal," and of course financial markets and investment banks, all have stakes in national and international political disputes. As a complex, multilayered process of struggle, it is hard to predict the precise outcomes and conflicts in each case. It seems clear, however, that the far-right avant-garde is often backed by powerful economical groups, particularly when it comes to disputes in developing and under-developed countries (Verweijen and Dunlap 2021).

\section{Conclusions}

In sum, this essay was an attempt at indicating underexplored but timely research questions that fall under the umbrella or so-called hybrid or asymmetric warfare. Our purpose was to shed light on a rigid power structure working in a decentralized manner, which intentionally produces an environment of permanent crisis in order to manage persons (and robots) on social media as swarms split in two groups. This involves broader power struggles involving national and international actors in a rapidly changing world, particularly in the aftermath of the 2008 crisis. Each nation-state has its own particularities, as we sought to show with the examples from Brazil, and yet available evidence strongly suggests a recurrent pattern of cyber-guerrilla operations. We expect that this paper may stimulate further comparative research on how cyber guerrillas are organized in different territories.

Funding Open access funding provided by LUT University (previously Lappeenranta University of Technology (LUT)).

Open Access This article is licensed under a Creative Commons Attribution 4.0 International License, which permits use, sharing, adaptation, distribution and reproduction in any medium or format, as long as you give appropriate credit to the original author(s) and the source, provide a link to the Creative Commons licence, and indicate if changes were made. The images or other third party material in this article are included in the article's Creative Commons licence, unless indicated otherwise in a credit line to the material. If material is not included in the article's Creative Commons licence and your intended use is not permitted by statutory regulation or exceeds the permitted use, you will need to obtain permission directly from the copyright holder. To view a copy of this licence, visit http://creativecommons.org/licenses/by/4.0/.

\section{References}

Abdin, C. 2021. From 'Networked Publics' to 'Refracted Publics': A companion framework for researching 'Below the Radar' studies. Social Media Society 7(1): 1-13.

Arthur, W.B. 2021. Foundations of complexity economics. Nature Reviews Physics 3: 136-145.

Bateson, G. 1958. Naven: A survey of the problems suggested by a composite picture of the culture of a New Guinea tribe drawn from three points of view, vol. 21. Stanford University Press.

Boyd, J. 1987. Destruction and creation. New York: US Army Command and General Staff College.

Brambilla, M., E. Ferrante, M. Birattari, and M. Dorigo. 2013. Swarm robotics: A review from the swarm engineering perspective. Swarm Intelligence 7(1): 1-41.

Cesarino, L. 2019. On digital populism in Brazil. PoLAR: Political and Legal Anthropology Review-Ethnographic Explainers, April 15.

Cesarino, L. 2020. When Brazil's Voters Became Followers. Anthropology News, September 14.

Cesarino, L. 2021. A desinformação como método: Bolsonaro e o novo regime de verdade na pandemia. Jacobin Brasil, February 9. 
Cesarino, L. in print. The Neuropolitics of Populist Antagonism in Brazil: Schismogenesis and Reverse Mimesis in pro-Bolsonaro Memetic Warfare.

Cinelli, M., G.D.F. Morales, A. Galeazzi, W. Quattrociocchi, and M. Starnini. 2021. The echo chamber effect on social media. Proceedings of the National Academy of Sciences 118: 9.

Chun, W. 2016. Updating to remain the same: Habitual new media. Cambridge, MA: The MIT Press.

Dardot, P., and C. Laval. 2014. The new way of the world: on neoliberal society. New York: Verso Books.

Gerovitch, S. 2004. From newspeak to cyberspeak: A history of Soviet cybernetics. Cambridge, MA: MIT Press.

Goldstein, A. 2019. The new far-right in brazil and the construction of a right-wing order. Latin American Perspectives 46(4): 245-262.

González-Bailón, S., and M. De Domenico. 2021. Bots are less central than verified accounts during contentious political events. Proceedings of the National Academy of Sciences 118: 11.

Gray, J., L. Bounegru, and T. Venturini. 2020. "Fake news as infrastructural uncanny. New Media \& Society 22(2): 317-341.

Jaitner, M.L., and H. Kantola. 2016. Applying principles of reflexive control in information and cyber operations. Journal of Information Warfare 15(4): 27-38.

King, A. 2006. The post-Fordist military. Journal of political and military sociology 34(2): 359.

Kühnlenz, F., and P.H.J. Nardelli. 2016. Dynamics of complex systems built as coupled physical, communication and decision layers. PLoS ONE 11(1): e0145135.

Kühnlenz, F., P.H. Nardelli, and H. Alves. 2018. Demand control management in microgrids: The impact of different policies and communication network topologies. IEEE Systems Journal 12(4): $3577-3584$.

Leirner, P. 2020. Hybrid warfare in Brazil: The highest stage of the military insurgency. HAU: Journal of Ethnographic Theory 10(1): 41-49.

Merrin, W. 2019. President troll: Trump, 4chan and memetic warfare. In Trump's media war, 201-226. Cham: Palgrave Macmillan.

Merrin, W., and A. Hoskins. 2020. Tweet fast and kill things: Digital war. Digital War 1: 184-193.

Mirowski, P. 2019. Hell is truth seen too late. Boundary 46(1): 1-53.

Nardelli, P.H., and F. Kühnlenz. 2018. Why smart appliances may result in a stupid grid: Examining the layers of the sociotechnical systems. IEEE Systems, Man, and Cybernetics Magazine 4(4): 21-27.

Oates, S. 2020. The easy weaponization of social media: why profit has trumped security for US companies. Digital War 1: 117-122.
Oreskes, N., and E. Conway. 2011. Merchants of doubt: How a handful of scientists obscured the truth on issues from tobacco smoke to climate change. New York, NY: Bloomsbury Publishing.

Santos, J.G., M. Freitas, A. Aldé, K. Santos, and V. Cunha. 2019. WhatsApp, política mobile e desinformação: A hidra nas eleições presidenciais de 2018. Comunicação \& Sociedade 41(2): 307-334.

Seger, E., S. Avin, G. Pearson, M. Briers, Ó. Heigeartaigh, and H. Bacon. 2020. Tackling threats to informed decision-making in democratic societies: Promoting epistemic security in a technologically-advanced world. Alan Turing Institute. https://doi.org/ 10.17863/CAM.64183.

Srnicek, N. 2017. Platform capitalism. Wiley.

Van Haaster, J., R. Gevers, and Sprengers, M. 2016. Cyber guerilla. Syngress.

Verweijen, J., and A. Dunlap. 2021. The evolving techniques of the social engineering of extraction: Introducing political (re) actions 'from above' in large-scale mining and energy projects. Political Geography, Advance Online Publication. https://doi.org/10. 1016/j.polgeo.2021.102342.

Letícia Cesarino is Associate Professor of Anthropology at the Federal University of Santa Catarina, Brazil. She holds a Ph.D. in cultural anthropology from University of California at Berkeley, USA. She has worked in the fields of anthropology of science and technology, digital anthropology, economic and development anthropology, globalization and post-colonial studies, on the following topics: cybernetics and systems theories; digital media, neoliberalism, conservative and post-truth populisms; biosafety; south-south cooperation, Brazil-Africa relations, southern globalizations, technology transfer.

Pedro H. J. Nardelli is Associate Professor (tenure track) in IoT in Energy Systems at LUT University, Finland, and holds a position of Academy of Finland Research Fellow. He received his doctoral degree in electrical/communications engineering from University of Oulu, Finland, and State University of Campinas, Brazil, following a joint supervision agreement. He leads the Cyber-Physical Systems Group at LUT and is Project Coordinator of the European consortium Framework for the Identification of Rare Events via Machine Learning and IoT Networks and of the project Swarming Technology for Reliable and Energy-aware Aerial Missions supported by JAES Foundation. 